\title{
SELEÇÃO DE Trichoderma spp. VISANDO AO CONTROLE DE Sclerotinia sclerotiorum, in vitro
}

\author{
SELECTION OF Trichoderma spp. SEEKING THE CONTROL OF \\ Sclerotinia sclerotiorum, in vitro
}

\section{Luciana Zago Ethur $^{1}$ Cláudia Zago Cembranel ${ }^{2}$ Antonio Carlos Ferreira da Silva ${ }^{3}$}

\begin{abstract}
Este trabalho teve por objetivo selecionar isolados de Trichoderma spp. com potencial de antagonismo sobre o fitopatógeno Sclerotina sclerotiorum, in vitro. Foram utilizados doze isolados de Trichoderma spp. e três isolados de $\mathbf{S}$. sclerotiorum nas técnicas "papel celofane - modificada" $e$ "confrontação direta". Com o desenvolvimento das técnicas in vitro, foram selecionados os isolados TSM1, J10 e II de Trichoderma spp. com melhor atividade antagonista, sobre os isolados de S. sclerotiorum.
\end{abstract}

Palavras-chave: fitopatógeno, Trichoderma spp., antagonismo, mofo branco.

\section{SUMMARY}

The objective of this work was to select isolates of Trichoderma spp. with potential of antagonism against Sclerotina sclerotiorum, in vitro. Twelve isolates of Trichoderma spp. and three isolates of S. sclerotiorum were used in the techniques "cling film - modified" and "direct confrontation". Based on the technique in vitro it the isolates TSM1, J10 and II of Trichoderma spp.were selected with better antagonistic activity, on the isolates of $\mathbf{S}$. sclerotiorum.

Key words: plant pathogens, Trichoderma spp., antagonistic, white mold.

Sclerotinia sclerotiorum é um fungo habitante de solo que causa a doença conhecida como mofo branco e cujos sintomas se caracterizam pela podridão úmida coberta por um micélio branco algodonoso na superfície do solo e/ou tecido hospedeiro produzindo eventualmente estruturas de resistência denominadas escleródios (CARDOSO, 1990).

Trichoderma spp. é um promissor agente de biocontrole. Segundo MELO (1998) Trichoderma spp. é um fungo natural do solo encontrado especialmente em solos orgânicos, que pode viver saprofiticamente ou parasitando outros fungos. $O$ presente trabalho visou selecionar isolados de Trichoderma spp. com potencial de antagonismo sobre o fitopatógeno Sclerotinia sclerotiorum, in vitro.

Foram utilizados doze isolados de Trichoderma spp. (2B1, 2B2, 2B6 e 2B22 de São Paulo - SP; C1, I1, J8, J9, J10, TSM1 e TSM2 de Santa Maria - RS; TW5 do CNPSO/EMBRAPA) e três isolados de Sclerotinia sclerotiorum (S1 tomateiro, S2 - alface e S3 - fumo de Santa Maria RS).

A técnica do papel celofane realizada por HOMECHIN (1986) REIS et al. (1995) e DURMAN et al. (1999) foi modificada quanto à inoculação do patógeno, alterando-se o local e o número de discos do patógeno. Ao invés de se colocar um disco de micélio do patógeno no centro

\footnotetext{
${ }^{1}$ Biólogo, Especialista em Biologia - Universidade Federal de Santa Maria (UFSM).

${ }^{2}$ Especializando - Curso de Especialização em Biologia, UFSM.

${ }^{3}$ Engenheiro Agrônomo, Professor, Doutor do Departamento de Biologia, Centro de Ciências Naturais e Exatas, UFSM, 97105-900, Santa Maria-RS. E-mail: acfsilva@ccne.ufsm.br. Autor para correspondência.
} 
da placa, foram colocados dois discos em bordas opostas. Cada tratamento teve quatro repetições. A inibição do crescimento micelial do patógeno foi medida $(\mathrm{cm})$ de acordo com o espaço existente entre as duas colônias de $\boldsymbol{S}$. sclerotiorum.

Neste experimento verificou-se a liberação de metabólitos (não-voláteis) pelos isolados de Trichoderma spp, devido a coloração (escura) diferenciada existente no meio de cultura e os diferentes graus de inibição quanto ao crescimento micelial de $\boldsymbol{S}$. sclerotiorum comparados com o controle (Tabela 1). A produção de metabólitos por Trichoderma foi evidenciada em trabalhos de BELL et al. (1982), REIS et al. (1995), APARECIDO \& FIGUEIREDO (1999) e DURMAN et al. (1999).

Os isolados de Trichoderma spp. que apresentaram maior antagonismo por antibiose ao $\boldsymbol{S}$. sclerotiorum isolado de tomateiro, alface e fumo, foram: TSM1 (94\% de inibição), J10 (93\%) e I1 (86\%). Segundo MELO (1998) muitas espécies de Trichoderma já estudadas possuem a capacidade de produzir metabólitos tóxicos, tais como antibióticos e enzimas líticas capazes de inibir propágulos de fungos fitopatogênicos.

$\mathrm{Na}$ técnica da confrontação direta foram utilizados os isolados I1, J10 e TSM1 de Trichoderma spp (selecionados na técnica anterior)

Tabela 1 - Antagonismo, in vitro, de isolados de Trichoderma spp. aos isolados de S. sclerotiorum - tomateiro (S1), alface (S2) e fumo (S3). Santa Maria - RS, 1999.

\begin{tabular}{|c|c|c|c|}
\hline \multirow[b]{2}{*}{ ISOLADO } & \multicolumn{3}{|c|}{$\begin{array}{c}\text { Distância }(\mathrm{cm}) \text { entre as bordas de duas colônias de isolados de } \\
\text { Sclerotinia sclerotiorum }{ }^{I}\end{array}$} \\
\hline & $\mathrm{S} 1$ & $\mathrm{~S} 2$ & S3 \\
\hline I1 & $5,92 a^{*}$ & $4,91 \mathrm{a}$ & $4,59 a$ \\
\hline $\mathrm{J} 10$ & $5,82 \mathrm{a}$ & $5,79 a$ & $5,14 \mathrm{a}$ \\
\hline TSM1 & $5,74 \mathrm{a}$ & $5,99 \mathrm{a}$ & $5,24 \mathrm{a}$ \\
\hline 2B22 & $3,41 \mathrm{~b}$ & $1,17 \mathrm{~cd}$ & $2,18 \mathrm{~b}$ \\
\hline TSM2 & $2,80 \mathrm{bc}$ & $1,16 \mathrm{~cd}$ & $4,52 \mathrm{a}$ \\
\hline J8 & $2,68 \mathrm{bcd}$ & $0,78 \mathrm{~cd}$ & $0,00 \mathrm{c}$ \\
\hline 2B6 & $2,60 \mathrm{bcd}$ & $0,12 \quad \mathrm{~d}$ & $0,00 \mathrm{c}$ \\
\hline J9 & $2,41 \mathrm{bcd}$ & $1,11 \mathrm{~cd}$ & $0,88 \mathrm{bc}$ \\
\hline TW5 & $2,11 \mathrm{bcd}$ & $1,54 \mathrm{c}$ & $0,31 \quad \mathrm{c}$ \\
\hline 2B1 & $2,03 \mathrm{bcd}$ & $0,91 \mathrm{~cd}$ & $0,19 \quad \mathrm{c}$ \\
\hline $\mathrm{C} 1$ & 1,17 cde & $4,05 \mathrm{ab}$ & $0,75 \mathrm{bc}$ \\
\hline $2 \mathrm{~B} 2$ & $1,05 \mathrm{de}$ & $2,16 \mathrm{bc}$ & $0,19 \quad \mathrm{c}$ \\
\hline CONTROLE & 0,00 & $0,00 \quad \mathrm{~d}$ & $0,00 \quad \mathrm{c}$ \\
\hline
\end{tabular}

${ }^{1}$ As colônias desenvolveram-se a partir de dois discos de inóculo, colocados em direção oposta, nas bordas das placas com meio BDA.

* Médias seguidas da mesma letra minúscula não diferem entre si (Teste de Tukey $-5 \%$ )

$\mathrm{CV}=11,979 \%$ e os três isolados de $\boldsymbol{S}$. sclerotiorum. Cada tratamento teve quatro repetições e o delineamento experimental foi em blocos casualizados.

As avaliações foram baseadas no critério de BELL et al. (1982), no qual se utilizou uma escala de notas variando de 1 a 5 , na qual em 1 Trichoderma cresce e toma toda placa e $5-\mathrm{O}$ patógeno cresce e toma toda placa.

Os três isolados de Trichoderma cresceram sobre o patógeno, sendo que não ocorreram diferenças significativas nas médias das notas entre os isolados TSM1 e I1 (ambos cresceram e tomaram menos de dois terços da placa), mas foram constatadas diferenças quando comparados ao isolado J10 (cresceu e tomou mais de dois terços da placa). $\mathrm{O}$ confronto direto entre o patógeno e o antagonista evidenciou que os três isolados de Trichoderma se utilizam de outras formas de antagonismo além da antibiose. De acordo com MELO (1998) a ação de Trichoderma se dá através da associação ou não dos mecanismos de parasitismo, antibiose e competição.

Ocorreu o aparecimento de uma halo (coloração escura) ao longo da linha de contato entre as colônias do antagonista e do patógeno sendo que este fato também foi observado por BELL $\boldsymbol{e t}$ al. (1982) e DURMAN et al. (1999). Os escleródios formados foram colonizados pelos isolados de

Trichoderma spp. pois estes se tornaram "moles", perdendo sua consistência característica. MELO (1991) comenta que o fungo Trichoderma tem sido encontrado parasitando escleródios, e que estes são estruturas resistentes ao parasitismo.

\section{REFERÊNCIAS BIBLIOGRÁFICAS}

APARECIDO, C.C., FIGUEIREDO, M.B. Antagonismo de Trichoderma viride a diferentes fungos fitopatogênicos. In: CONGRESSO PAULISTA DE FIPATOLOGIA, 22, 1999, Jaboticabal, SP. Anais... Jaboticabal : Grupo Paulista de Fitopatologia, 1999.

BELL, D.K., WELLS, H.D., MARKHAM, C.R. In vitro antagonism of Trichoderma species against six fungal plant pathogens. Phytopathology, v.72, n.4, p.379-382, 1982 .

CARDOSO, J.E. Doenças do feijoeiro causadas por patógenos de solo. Goiânia : EMBRAPA-CNPAF, 1990. 30p. (EMBRAPA-CNPAF. Documentos, 30).

CARRASCO, A. Nuevos hospedantes de Sclerotinia sclerotiorum, agente causal del moho blanco. Rev. Fitopatología Venezuelana, v.10, n.1, p.17-18, 1997. 
DURMAN, S., MENENDEZ, A., GODEAS, A. Evaluación de Trichoderma spp. como antagonista de Rhizoctonia solani in vitro y como biocontrolador del damping-off de plantas de tomate en invernadero. Revista Argentina de Microbiología, v.31, p.13-18, 1999.

HOMECHIN, M.. Produção e liberação de substâncias inibidoras do crescimento de patógenos, por Trichoderma harzianum em meio de BDA. In: REUNIÃO SOBRE CONTROLE BIOLÓGICO DE DOENÇAS DE PLANTAS. 1, 1986, Piracicaba, SP. Anais... Piracicaba : Fundação Cargill, 1986.

MELO, I.S. de. Potencialidades de utilização de Trichoderma spp. no controle biológico de doenças de plantas. In
BETTIOL,W. (org.) Controle biológico de doenças de plantas. Jaguariúna : EMBRAPA-CNPDA, 1991. Cap. 9.

388p. (EMBRAPA-CNPDA. Documentos, 15). Agentes microbianos de controle de fungos fitopatogênicos. In: MELO, I.S., AZEVEDO, J.L. Controle biológico. Jaguariúna :EMBRAPA, 1998. V.1. Cap. 1. 262p.

REIS, A., OLIVEIRA, S.M.A. de, MENEZES, M. et al. Potencial de isolados de Trichoderma para biocontrole da murcha de Fusarium do feijoeiro. Summa Phytopathologica, São Paulo, v.21, n.1, p.16-20, 1995.

Ciência Rural, v. 31, n. 5, 2001. 